$\begin{array}{ll}\text { Research Square } & \begin{array}{l}\text { Preprints are preliminary reports that have not undergone peer review. } \\ \text { They should not be considered conclusive, used to inform clinical practice, } \\ \text { or referenced by the media as validated information. }\end{array}\end{array}$

\title{
Community-based interventions for preventing COVID-19 transmission in low- and middle-income countries: A systematic review
}

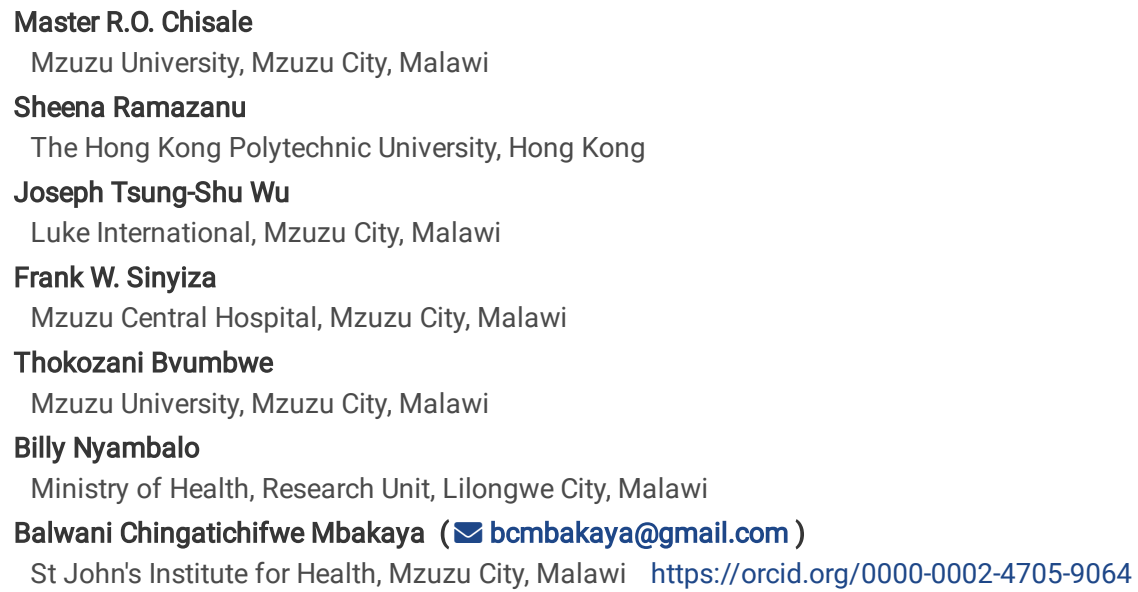




\section{Abstract}

Background World Health Organisation (WHO) has approved and recommended several public health measures to halt the Coronavirus Disease 2019 (COVID19) pandemic. The implementation of recommended interventions vary between higher income and Low and Middle-Income Countries (LMICs). The economical constraints within LMICs posed challenges in accessing resources for COVID-19 prevention. The study aimed to identify the workable communitybased interventions being utilised in LMICs.

Main body We applied systematic review approach for this study. Included articles were searched in eight online databases. The analysis was guided by the acceptable of best practice developed by the PROSPERO and COCHRANE for systematic search and selection of articles using pre-defined search terms. Furthermore, a PRISMA flow diagram was used to show the number of articles retrieved, retained, excluded with rationales given for every action. Studies conducted on community-based intervention for preventing COVID-19 and levels of knowledge, attitudes and practice (KAP) on community-based intervention for preventing COVID-19 regardless of the design were included. A mixed method appraisal tool (MMAT) was used to appraise studies.

Six studies from LMICs were included for detail analysis after the systematic review screening process from 10,100 articles. The quality assessment using MMAT tool appraised these articles were all in highest quality. Among the six articles, 10 community-based interventions were implemented in LMICs. The three key workable and implemented interventions are: use of masks, social distance and hand wash. The review identified varying levels of KAP between LMICs and social-demographical factors affecting KAP in these settings.

Conclusion This systematic review has identified the community-based interventions implemented in LMICs to prevent COVID-19 during the pandemic and key factors affecting the level of KAP among the population. This study re-affirms the importance of effective and suitable implementation of the identified interventions. More studies need to be conducted in LMICs to establish the effectiveness and adoption of the implemented and recommended interventions.

\section{Background}

The World Health Organization (WHO) declared the coronavirus disease2019 (COVID-19) outbreak a public health emergency of international concern (PHEIC) on $30^{\text {th }}$ January 2020(1). As the world's population faces an unprecedented global health emergency due to the outbreak of novel coronavirus COVID-19, a strong, resilient healthcare system is key to achieving sustainable improvements in community health $(2,3)$. This can be demonstrated by putting systems in place to avoid further spread of the disease. Several measures have been approved and recommended by WHO to be observed by the public as a means of halting the spread of the COVID-19 pandemic $(4,5)$. These measures include social distancing, lockdown, covering of mouth when coughing, frequent hand washing with soap and water, use of sanitizers, use of face mask, etc(6,7). Much as the proposed measures sound simple and doable; however, its application may vary between developed and developing countries as well as within developing countries. More challenges are faced by the Low- and Middle-Income countries (LMICs) due to resource constraints(3,8). Many LMICs especially in the rural communities, have challenges to access portable clean water, hand washing stations, access to hand washing soap, and money to buy face mask $(9,10)$. Little is known on how the communities in the developing countries are coping with the pandemic and the what and how the recommended measures are applied and if there are other workable approaches. Therefore, this review aimed at consolidating and synthesising information from published articles on community-based interventions so far used since the outbreak of COVID-19 pandemic. The targeted outcomes were to identify the interventions implemented in the community and to assess the level of KAP on community-based COVID-19 preventive measures. The questions that were addressed by this review are: (1) What are the community-based interventions so far used for preventing COVID-19 transmission in LMICs? (2) What is the level of KAP among people on community-based intervention for preventing COVID-19 pandemic?

\section{Methodology Protocol}

This systematic review was guided by the guidelines developed by the PROSPERO for systematic search and selection. PROSPERO is an international database for registering systematic reviews in various professions including the health sector(11). The protocol was published in the PROSPERO database with registration number CRD42020204984. Details about the protocol have been published elsewhere(10). PRISMA (Preferred Reporting Items for Systematic Reviews and Meta-Analyses) flow diagram was used to show the number of articles retrieved, retained, excluded with justifications rendered for every action. A PRISMA is a set of items founded on research evidence that improves and supports the reporting clarity of the systematic reviews and meta-analyses(12). A Mixed Method Appraisal Tool (MMAT) was used to appraise the quality of the studies included(13).

\section{Inclusion criteria}

Studies were eligible for inclusion in this systematic review based on the following criteria: (1) study of any design; (2) conducted in low and/or middle income countries; (3) studies conducted in community settings; and (4) studies which focussed on community-based interventions for preventing COVID-19, and level of KAP on community-based intervention for preventing COVID-19.

\section{Exclusion criteria}

Articles were excluded from this systematic review if they were: (1) reviews, perspectives, communications; (2) written in languages other than English; and (3) were conducted in high income countries. 
The following eight database sources were used to gather the required research articles: PubMed, EMBASE, PsycINFO, AMED, CINAHL, DOAJ, Medline and Google Scholar. MeSH database search in PubMed was conducted to identify search terms and keywords. These keywords combined with Boolean operations OR and AND were used to search and retrieve articles from the databases. The search strategy was confined to research articles published from December 2019 to August 2020. The following key search words were used; Transmission OR spread AND COVID-19 OR COVID OR corona virus, prevent* OR avoidance OR control OR limit AND COVID-19 OR COVID OR corona virus, community AND transmission OR spread AND COVID-19 OR COVID OR corona virus, community AND prevention OR avoidance OR control OR limit AND COVID-19 OR COVID OR corona virus, community OR family OR school OR workplace OR neighbour? OR household OR local AND transmission OR spread AND COVID-19 OR corona virus, community OR family OR school OR workplace OR neighbourhood OR household OR local AND prevention OR avoidance OR control OR limit AND COVID-19 OR COVID OR corona virus AND developing countries OR low-income countries OR middle-income countries. Knowledge OR attitude OR practice AND COVID-19 OR corona virus.

Efforts were also made to identify both published and unpublished studies by manually searching conference proceedings and pre-prints to identify additional unpublished studies. Thereafter, identified studies were checked to determine their eligibility.

\section{Study selection}

Articles identified from the databases were imported to Mendeley Reference Management Software(14). Thereafter, the title, abstract and finally full articles were reviewed against the set inclusion criteria.

\section{Data collection process}

The process of data extraction started with a database search of relevant articles as described above and following the PRISMA guidelines (see Figure 1). Titles and/or abstracts of studies were retrieved and studies that potentially met the inclusion criteria as outlined above were identified. The full texts of potentially eligible studies were retrieved and independently assessed for eligibility by two authors. The inconsistencies between the two authors (MC \& BC) over the eligibility of some studies were discussed and resolved with a third author (SR). A table was used to extract data from the studies included for assessment of study quality and synthesis evidence. The details included; author, year of study, type of participants, age, setting, country, sample size, study design and methods, study purpose/objectives, study outcomes and results. All relevant information was extracted from each study, summarized and documented.

\section{Search outcome}

An initial search of the databases and other sources yielded 10,100 articles. The titles of the identified articles were assessed and 10,028 articles were removed because they were either duplicates or abstracts only. Of the remaining 68 articles, 62 were excluded because they did not meet the inclusion criteria and were conducted in high income countries or not in community settings. The remaining six articles met our inclusion criteria (see Figure 1).

\section{Quality appraisal}

Quality of the design and reporting system were the main focus at this stage. Three authors (MC, SR \& BM) reviewed independently to assess the risk of bias in the included studies. The MMAT(13) was used to appraise the six studies included in the review critically. MMAT is a validated checklist used to appraise the quality of studies included in any systematic review with a quantitative, qualitative and mixed methods approach. The MMAT has two general screening questions applicable to all study designs: 1) Are there clear research questions? 22 ) Do the collected data allow to address the research questions? $₫$ The MMAT appraises the following study methodologies and designs: qualitative, quantitative randomised controlled, quantitative non-randomized, quantitative descriptive and mixed methods study designs. The tool is divided into five components and each component is designed to assess the quality of a specific study design. For example, assessment criteria for assessing for quantitative descriptive studies included: 1 ) Is the sampling strategy relevant to address the research question? 2) Is the sample representative of the target population? 3) Are the measurements appropriate? 4) Is the risk of nonresponse bias low? 5) Is the statistical analysis appropriate to answer the research question?

According to the latest version of MMAT tool(13), it is discouraged to calculate an overall score from the ratings of each criterion. Instead, it is advised to provide a more detailed presentation of the ratings of each criterion to better inform the quality of the included studies. Furthermore, excluding studies with low methodological quality is also discouraged.

The actual rating uses a "yes" or "no" or "can't tell" with comments where necessary. Overall, the more the "yes" score, the better the quality of the study. MMAT was chosen to appraise studies in this review because it can simultaneously appraise studies of different designs, which was anticipated but turned to have included cross-sectional studies only which qualified according to our inclusion criteria. Therefore, we used the MMAT section which appraises the quantitative descriptive study designs. 


\section{Data synthesis}

We identified community-based interventions used to prevent COVID-19 in low- and middle-income countries. Community-based intervention in this systematic review was defined as (1) a setting other than a health clinic or hospital where interventions were conducted (e.g. home, school, church, neighbourhoods, or workplace), and (2) community as a target (people found in the community setting). A subset analysis was done, categorized by type of community-based intervention for preventing COVID-19 (use of masks, social distancing, quarantine, hand washing, hand sanitizers, sanitation, water etc), and level of KAP on community-based intervention for preventing COVID-19). A narrative synthesis was conducted based on the content analysis of the included articles.

\section{Results}

\section{Quality appraisal}

Three authors independently reviewed the six articles; $(4,7,15-18)$ included in this systematic review. All the included articles were found to be of highest quality (scored "yes" on all the methodological quality criteria) except one study by Usman et al., (2020) which scored a "no" on one criterion (Is the sample representative of the target population?) in their study, the sample representativeness was not clearly stated. Therefore the included studies in this systematic review are overall of high quality and synthesised evidence can be relied upon.

\section{Study characteristics}

Six studies $(4,7,16,18-20)$ met the inclusion criteria for this systematic review. All the included studies were conducted during the COVID-19 pandemic and published between the months of April and August, 2020. Of these, one study was conducted in Indonesia(18), one study was conducted in Nigeria and Egypt(19), one study was conducted in Democratic Republic of Congo (DRC), Ethiopia and South Korea(21), one study was conducted in Nigeria(20), and two studies were conducted in Uganda $(4,7)$. See table 2 . This shows that the majority of the studies were conducted in Africa, except one study which was conducted in Indonesia(18).

In terms of design, all the studies included in this systematic review used quantitative descriptive designs (cross-sectional).

Data collection was primarily through online survey in all the six studies (See Table 2).

A total of three studies were conducted country-wide through online survey $(7,15,16)$. Two studies were conducted in provinces/states(18,20). One study was conducted in a market setting among vendors(4)

The study population age ranged from 12 years (18) to more than 60 years (4). The number of participants in each study varied from 248 (4) to 1,763 (7).

\section{Summary of the findings}

Studies included in this review were analysed based on the following two outcomes: (1) Types of community-based interventions for preventing COVID-19 transmission in LMICs, and (2) Level of KAP on community-based COVID-19 preventive measures in LMICs. These sub-categories were generated from the objectives of the study. The authors of this systematic review created graphs which summarizes the findings from the included articles. The presentation and interpretation of the results follow these categories as narrated below.

\section{Type of community-based intervention for preventing COVID-19}

We identified 10 community-based interventions for preventing COVID-19 in the studies included in this systematic review. These are: (1) use of masks; (2) social distance; (3) hand wash; (4) hand sanitizers; (5) isolation; (6) restriction of gathering; (7) cleaning of surfaces; (8) covering of mouth when coughing; (9) avoidance of public; and (10) lockdown (See figure 2). Among the ten types of interventions, use of masks, social distance and hand wash were top three strategies implemented in the LMICs settings. The least implemented interventions were lockdown and avoidance of public transport. All of the identified community-based interventions for preventing COVID-19 which were reported in the articles included in our review, were adopted from those recommended by WHO. Studies looked at some or all of the WHO recommended interventions as a package. However, in one study(18) conducted in Indonesia, their investigations only focused at one preventive measure (social distance) (See figure 2). The authors managed to retrieve results for two countries only (Ethiopia and DRC) in a study by (16) who conducted their study in three countries (DRC, Ethiopia, \& South Korea). The results from South Korea were not used in this review because South Korea is a high income country(22) and falls in the exclusion criteria for this systematic review.

\section{Level of KAP on community-based interventions for preventing COVID-19}

Five studies looked at the level of KAP on community-based intervention for preventing COVID-19 in LMIC $(4,7,18-20)$. However, one study $(16)$ only looked at the level of practice on community-based intervention for preventing COVID-19 (See Figure 3). The level of knowledge ranged from $62 \%$ in a study conducted 
in Egypt and Nigeria (19) to $99 \%$ in a study conducted in Indonesia (18). Age (18-39 years), education (college/bachelors), and background of respondents were factors influencing knowledge levels(19). While in a study conducted by Doherty et al. (2020) (20) in Nigeria, the knowledge of the outbreak of COVID-19 was influenced by the age $(p<0.05)$, gender $(p<0.05)$, level of education $(p<0.05)$, marital status $(p<0.05)$ and employment status $(p<0.05)$. In a study conducted in Uganda by Usman et al. (2020)(4), found that the percentage score among those having their phones connected and those not having connected to the internet on knowledge was $77.00 \%$ and $74.53 \%$, respectively.

Hager et al. (2020) (19) found that participants within the 18-29 years age range were 1.4 times (95\% Cl: $0.55-0.89 ; p=0.004)$ more likely to be knowledgeable than other age groups. Respondents with a high school education were at least 4.7 times (95\% Cl: $0.15-144.7 ; p=0.73)$ more likely to have satisfactory knowledge about COVID-19 than those with no formal education (19). In the same study, Hager et al (2020)(19), found that Egyptians were 1.8 times (95\% Cl: $0.43-0.74 ; \mathrm{p}<0.001)$ more likely to have more satisfactory knowledge than Nigerians. A study conducted in Uganda by Ssebuufu et al. (2020) (7), found that the mean knowledge scores significantly differed across genders, marital status, profession and location ( $p<0.05)$ but did not significantly differ across age groups $(p>0.05)$ in univariate analysis and ordered logistic regression analysis.

In a study conducted in Indonesia by Yanti et al., (2020)(18), found that the level of attitude on community-based interventions for preventing VOVID-19 was low (59\%), while a study conducted in Nigeria by Doherty and colleagues (2020) found that the level of attitude was higher (94\%) than the rest of the studies included in this review. There was a significant difference $(p=0.0055)$ in the percentage score for attitude among those connected $(86.92 \%)$ and those not connected $(79.41 \%)$ to the internet (Usman et al., 2020). The percentage score for attitude was significantly different $(P=0.0358)$ among those with one source $(73.04 \%)$ and those with four (82.68\%) sources of information (4).

Hager et al. (2020) found that age, gender, level of education, background, and nationality had a significant impact on the attitude towards COVID-19. The older the respondents, the better their attitude towards the disease with an odds ratio ranging from 1.34 (95\% $\mathrm{Cl}$ : 1.06-1.74; $p=0.019)$ to 6.65 (95\% $\mathrm{Cl}$ : $0.17-$ 206.9; $p=0.692$ ). The level of education, background, and nationality greatly affected the perception of global and community response to curbing the spread of COVID-19 and preventing the occurrence of any future pandemic. Furthermore, female participants were 1.59 times $(95 \% \mathrm{Cl}$ : 1.27-1.99; $\mathbb{p} p<0.001)$, more likely to have a positive attitude towards COVID-19 than males, and Nigerians were 11 times $(95 \%$ Cl: $7.57-13.47 ; p<0.001)$ more likely to have a positive attitude than Egyptians (19). In a study conducted by Yanti et al., (2020) (18) in Indonesia, found that the respondents' educational and occupational attainment, such as bachelor graduate or civil servant, influenced their positive attitudes towards social distancing. Furthermore, the respondents who had good knowledge, more than half (58\%) had a positive attitude (18).

Level of practice was lowest (19\%) in a study conducted by Lee et al. (2020)(16) in Ethiopia and DRC. Nigeria and Egypt registered the highest level of practice (96\%) in a study conducted by Hager et al., (2020)(19). A study conducted by Usman et al., (2020)(4) in Uganda, found that there was a positive correlation between attitude and practices $(r=0.17, p=0.007)$, as well as their knowledge with practices $(r=0.29, p<0.001)$.

In a study conducted in Uganda by Usman et al., (2020)(4), found that the percentage score among those having their phones connected and those not having connected to the internet on practices were $78.49 \%$ and $75.08 \%$, respectively. Furthermore, they found that the percentage score for practices was significantly different $(p=0.0058)$ among individuals with no formal education (54.29\%) and those with primary $(75.24 \%)$, secondary $(77.03 \%)$, and tertiary (80.16\%) levels of education. Usman et al., (2020)(4), further found that the percentage score for practice was significantly different $(p<0.0001)$ between those with one source (69.19\%) and those with two (89.07\%), three (87.23\%), four (92.12\%), and more than four (86.15\%) sources of information. The practice of respondents was significantly associated with profession and location of participants in the ordered logistic regression $(p<0.001)$ in a study conducted in Uganda by Ssebuufu et al., (2020)(7). For example, being a health worker was significantly associated with good practice (aOR: 2.9 (1.95-4.2). In a study conducted in Nigeria by Doherty et al., (2020)(20), found that both age $(p=0.03)$ and level of education $(p<0.05)$ influenced the respiratory and personal hygiene of the respondents

\section{Discussion}

To the best of our knowledge, this is the first systematic review conducted with an aim to identify workable and implemented community-based interventions for preventing COVID-19 transmission. This systematic review also identified the level of KAP on community-based intervention for preventing COVID-19 among participants in LMICs. Authors acknowledge other types of reviews (min-reviews, scoping, etc) conducted in area of COVID-19 (23,24). However, the current systematic review is unique in that its protocol is registered in a PROSPERO database, which is a register for systematic reviews. Furthermore, this systematic review focused on community-based intervention in LMICs unlike the other previous reviews. Authors searched for research articles that used community-based interventions for preventing COVID-19 in LMICs, and also articles on level of KAP on the community-based interventions published from December 2019 to August 2020. This systematic review identified six articles and synthesized its findings based on the type of community-based intervention used to prevent Covid-19 in LMIC. The review further synthesised the findings based on the level of KAP among the participants in the communities. The review identified 10 plus types of community-based interventions, namely: (1) use of masks; (2) social distance; (3) hand wash; (4) hand sanitizers; (5) isolation; (6) restriction of gathering; (7) cleaning of surfaces; (8) covering of mouth when coughing; (9) avoidance of public; and (10) lockdown. MMAT was used to appraise the methodology of the articles included in this systematic review. Overall, all the six studies included in this systematic review were of 
high/good quality. Therefore, the outcome of this synthesis can be relied upon to inform education, practice, and policy regarding community-based interventions for preventing COVID-19 transmission in LMICs.

The findings of this systematic review indicate that the most studied community-based interventions identified in the six studies included in this systematic review were use of mask, social distance and hand washing. The least studied community-based interventions were lockdown and avoidance of public transport, which were studied in DRC, Ethiopia and Nigeria(16,20). WHO emphasizes on frequent hand washing as one of the most effective intervention to prevent COVID-19 besides other measures such as social distance, use of mask etc $(1,5)$. Hand washing has been relied upon for decades as a cheap and single most effective intervention in reducing respiratory infections $(9,25-27)$. Lockdown was reported in one study (20) out the six studies included in this systematic review. The scarcity of lockdown as a community-based intervention could be ascribed to controversies surrounding on its implementation in the LMICs, where people in these countries protested against the intervention due to its anticipated socio-economic implications(28-30). Looking at the magnitude of COVID-19 pandemic, the six studies so far identified may not be enough to provide a clear direction on policy and practice. As such, more studies are needed which should put more emphasis on the effectiveness of the community-based intervention for preventing COVID-19.

All of the community-based interventions identified in this systematic review are in line with those recommended by WHO $(1,4,5)$. However, future studies should consider analysing each intervention separately and not as a lamp some/package as is the case in the current studies. If countries in the LMICs scale up these identified community-based interventions, it can help to drastically control the spread of COVID-19 and its consequences such as death, social and economic disruptions among people living in LMICs. This is because the identified interventions used in the included articles are scientifically proven, validated and recommended by WHO $(2020)(4,5,31)$.

The level of KAP among community members is key for any intervention to be effective. This is why we thought of investigating the level of KAP on the implemented community-based interventions. This systematic review also found varying levels of KAP on community-based interventions for preventing COVID-19. For example, the review found that the level of knowledge ranged from $62 \%$ (19) to $99 \%$ (18). The level of knowledge in the identified studies was reported to have been influenced by age (18-39 years), education (college/bachelors), background of respondents, gender, marital status, and employment status $(19,20)$. LMICs should invest more in educating its citizens in order to improves their knowledge on health literacy. There is sufficient evidence that well educated people are always healthier and engage in healthier behaviours(32).

The level of attitude in the articles included in this systematic review ranged from as low as $59 \%$ (18) to as high as $94 \%$ (20). The findings of this review have also revealed that age, gender, level of education, background, and nationality were reported to have had a significant impact on the attitude towards community-based COVID-19 preventive measures. The results from the six articles included in this systematic review, confirms the fact that knowledge affects one's attitude. For example, there was a significant difference $(p=0.0055)$ in the percentage score for attitude among those connected $(86.92 \%)$ and those not connected $(79.41 \%)$ to the internet (4), owing to access to information which might have improved their knowledge. Furthermore, the percentage score for attitude was significantly different $(P=0.0358)$ among those with one source $(73.04 \%)$ and those with four (82.68\%) sources of information (4).

Level of practice ranged from $19 \%(16)$ to $96 \%(19)$. The review found that there was a positive correlation between attitude and practices $(r=0.17, p=0.007)$, as well as their knowledge with practices $(r=0.29, p<0.001)$ in a study conducted in Uganda (4). Attitude is touted as one of the variables that influence intention to practice. A positive or negative attitude towards behaviour will either increase or decrease respectively, the intention to behave and recognition of the behaviour (33). Age and level of education were among the factors that influenced practice on community-based intervention for preventing COVID-19. The findings of this systematic review agree with those of a study by (34) in which they stated that sex, sources of information, and education level are some of the possible factors that could influence the knowledge, attitude, and practices. Knowledge is essential in determining people's behaviour and practices especially during any disease outbreak (34). This is because knowledge level influences their attitude and practices toward COVID-19 (35). It is therefore important for LMICs to prioritise and implement policies that enhance socio-economic drivers affecting knowledge, attitude and practice in order to succeed in the prevention of COVID-19 and other diseases of poverty such as TB.

\section{Limitations of the study}

The following are the limitations of this systematic review: Firstly, the review was limited to studies written in English, which might have led to some bias because articles in other languages could have contributed significantly to this systematic review in terms of study outcomes. Secondly, all the articles included in this review were conducted in LMICs. As such, the review may not be generalizable to other global settings. Thirdly, data collection methods (online) used in the articles included in this systematic review, may have targeted literate and economically sound people. i.e. only reached out to participants who has access to technology and know-how to fill it. This might have led to potential participant selection bias.

Despite these shortfalls, this review has identified community-based intervention for preventing COVID-19 in LMICs. The review has also generated evidence on the level of KAP on community-based intervention for preventing COVID-19 in LMICs. 
The findings of this systematic review inform practitioners, policy makers and researchers about the community-based interventions so far used for preventing COVID-19 transmission in LMICs, and the level of KAP among people on community-based intervention for preventing COVID-19 pandemic. The findings of this systematic review show direction which can be easily adopted in future when similar outbreaks occur in LMICs. Furthermore, some of the interventions identified in this systematic review may also be applied to prevent some of the diseases of poverty such as TB, influenza, diarrhoeas which are very common in LMICs if it can further be encouraged beyond Covid-19 era. Governments in LMICs are encouraged to promote the interventions identified in this systematic review in order to further halt the spread of COVID-19 and other related infections such as TB, influenza, and diarrhoea.

\section{Conclusion}

This systematic review has identified the community-based interventions implemented in LMICs to prevent COVID-19 during the pandemic. Furthermore, level of KAP among the population on the community-based interventions for preventing COVID-19 were unveiled. The findings of this review, re-affirms the importance of effective implementation of the identified interventions which are in line with those recommended by WHO (WHO, 2020). More studies need to be conducted in LMIC to establish the effectiveness of the intervention identified in this systematic review and those recommended by WHO.

\section{Abbreviations}

$\begin{array}{ll}\text { LMIC } & : \text { Low- and Middle-Income Countries } \\ \text { KAP } & : \text { Knowledge Attitude and Practice } \\ \text { TB } & : \text { Tuberculosis } \\ \text { DRC } & : \text { Democratic Republic of Congo } \\ \text { AMED } & : \text { AMED Allied and Complementary Medicine } \\ \text { CINAHL } & : \text { Cumulative Index of Nursing and Allied Health Literature } \\ \text { COCHRANE : Cochrane database of systematic reviews } \\ \text { COVID-19 } & : \text { coronavirus disease 19 } \\ \text { DOAJ } & : \text { The Directory of Open Access Journals } \\ \text { EMBASE } & : \text { Excerpta Medica dataBASE } \\ \text { MMAT } & : \text { The Mixed Methods Appraisal Tool } \\ \text { PRISMA } & : \text { Preferred Reporting Items for Systematic Reviews and Meta-Analyses } \\ \text { PROSPERO } & : \text { The International Prospective Register of Systematic Reviews } \\ \text { PsycINFO } & : \text { Psychological Information Database } \\ \text { WHO } & : \text { World Health Organisation }\end{array}$

\section{Declarations}

\section{Ethics approval and consent to participate}

Not applicable

\section{Consent for publication}

Not applicable

\section{Availability of data and material}

The data and materials used in this systematic review are available from the corresponding author on request.

\section{Competing interests}

The authors declare no competing interests.

\section{Funding}


The researcher contributed their own time for this study and Luke International provided communication resources for internet with research funding from Pingtung Christian Hospital research grant (grant number: PS-IR-109001).

\section{Author contributions}

Design of the literature review: MC, FS, JTSW \& BCM

Protocol writing and publication in PROSPERO: MC, FS, JTSW \& BCM

Literature search: MC, FS, JTSW, BN, TB, SR \& BCM

Data analysis: MC, FS, JTSW, BN, TB, SR \& BCM

Manuscript writing: MC, FS, JTSW, BN, TB, SR \& BCM

Critical revision or important intellectual content: MC, FS, JTSW, BN, TB, SR \& BCM

All authors have read and approved the manuscript

\section{Acknowledgement}

Not applicable

\section{References}

1. WHO. WHO Declaration of Covid 19 as Global Pandemic. 2020; Available from: https://www.who.int/news-room/detail/27-04-2020-who-timeline---covid19

2. Chowdhury R, Luhar S, Khan N, Reza S, Imran C, Oscar M. Long - term strategies to control COVID - 19 in low and middle - income countries: an options overview of community - based, non - pharmacological interventions. Eur J Epidemiol [Internet]. 2020;35(8):743-8. Available from: https://doi.org/10.1007/s10654-020-00660-1

3. Omaka-amari LN, Aleke CO, Obande-ogbuinya NE, Ngwakwe PC, Nwankwo O, Afoke EN. Coronavirus ( COVID-19) Pandemic in Nigeria: Preventive and Control Challenges within the First Two Months of Outbreak. 2020;2020(June):87-97.

4. Usman IM, Ssempijja F. Community Drivers Affecting Adherence to WHO Guidelines Against COVID-19 Amongst Rural Ugandan Market Vendors. 2020;8(July).

5. WHO. Responding to community spread of COVID-19: Interim guidance. 2020;

6. Aprihatin Y, Padang UN, Author C. COVID-19 PROMOTION AND PREVENTION MEASURES IN THE. 2020;4(1):35-9.

7. Ssebuufu R, Sikakulya FK, Binezero SM, Wasingya L, Nganza SK, Ibrahim B, et al. Awareness, knowledge, attitude and practice towards measures for prevention of the spread of COVID-19 in the Ugandans: A nationwide online cross-sectional Survey. 2020;1-28.

8. WHO. COVID-19 COVID-19; Information, Health Emergency Assessment, Risk. World Heal Organ African Reg website [Internet]. 2020;1-11. Available from: https://apps.who.int/iris/bitstream/handle/10665/332150/SITREP_COVID-19_WHOAFRO_20200520-eng.pdf

9. Mbakaya, B.C.; Lee, P.H.; Lee RLT. Hand Hygiene Intervention Strategies to Reduce Diarrhoea and Respiratory Infections among Schoolchildren in Developing Countries: A Systematic Review. Int J Environ Res Public Heal. 2017;14(371).

10. Balwani Mbakaya, Frank Sinyiza, Joseph Wu MC. Community-based interventions for preventing COVID-19 transmission in low- and middle-income countries: A systematic review. PROSPERO [Internet]. 2020; Available from: https://www.crd.york.ac.uk/prospero/display_record.php? ID=CRD42020204984

11. Booth A, Clarke M, Ghersi D, Moher D, Petticrew M SL. An international registry of systematic-review protocols. Lancet. 2011;377(9760):108.

12. Moher D, Liberati A, Tetzlaff J, Altman DG GP. Preferred reporting items for systematic reviews and meta-analyses: the PRISMA statement. PLoS Med. 2009;6(7).

13. Hong GN, Pluye P, Fàbregues S, Bartlett G, Boardman F, Cargo M, Dagenais P, Gagnon M, Griffiths F, Nicolau B, O'cathain A, Rousseau M \& VI. MIXED METHODS APPRAISAL TOOL (MMAT) VERSION 2018 User guide. Registration of Copyright (\#1148552),. Canadian Intellectual Property Office, Industry Canada. 2018.

14. Mendeley. Mendeley-Desktop-1.19.4-win32,. 2020; Available from: https://www.mendeley.com/download-desktop-new/\#download.

15. Hager E, Odetokun IA, Bolarinwa O, Zainab A, Okechukwu O A-MA. Knowledge, attitude, and perceptions towards the 2019 Coronavirus Pandemic: A binational survey in Africa. PLoS One. 2020;7(15).

16. Lee H, Moon SJ, Ndombi GO, Kim K, Berhe H, Nam EW. COVID-19 Perception , Knowledge, and Preventive Practice: Comparison between South Korea, Ethiopia , and Democratic Republic of Congo. 2020;2020(June):66-77.

17. Doherty FV, Odeyemi OA, Adeola A, Amolegbe O AF. Evaluation of knowledge, impacts and government intervention strategies during the COVID - 19 pandemic in Nigeria. Data Br. 2020; 
18. Budi Yanti, Eko Mulyadi, Wahiduddin, Revi Gama Hatta Novika, Yuliana Mahdiyah Da'at Arina, Natalia Sri Martani N. Community Knowledge, Attitude and Behaviour Towards Social Distance Policy as a means of Preventing Transmission of Covid-19 in Indonesia. J Adm Kesehat Indones. 2020;8(1).

19. Hager E, Id IAO, Id OB, Zainab A. Knowledge, attitude, and perceptions towards the 2019 Coronavirus Pandemic: A bi-national survey in Africa. 2020;113. Available from: http://dx.doi.org/10.1371/journal.pone.0236918

20. Doherty F V, Odeyemi OA, Adeola A, Amolegbe O, Eyitayo F. Evaluation of knowledge, impacts and government intervention strategies during the COVID 19 pandemic in Nigeria. Data Br [Internet]. 2020;32:106177. Available from: https://doi.org/10.1016/j.dib.2020.106177

21. Lee H, Moon SJ, Ndombi GO, Kim K, Berhe H \& NE. COVID-19 Perception, Knowledge, and Preventive Practice: Comparison between South Korea, Ethiopia, and Democratic Republic of Congo. 2020;

22. Fantom N. The World Bank's Classification of Countries by Income. 2016;(January).

23. Khadka S, Hashmi FK, Usman M. Preventing COVID - 19 in low - and middle - income countries. Drugs Ther Perspect [Internet]. 2020;36(6):250-2. Available from: https://doi.org/10.1007/s40267-020-00728-8

24. Jan H, Faisal S, Khan A, Khan S, Usman H, Liaqat R. COVID-19: Review of Epidemiology and Potential Treatments Against 2019 Novel Coronavirus. 2020;8(2):1-13.

25. Luby, S.P.; Agboatwalla, M.; Feikin, D.R.; Painter, J.; Billhimer, W.; Altaf A. H, R.M. Effect of hand washing on children's health: A randomised controlled trial. Lancet. 2005;366,:225-233.

26. Patel, M.K.; Harris, J.R.; Juliao, P.; Nygren, B.; Were, V.; Kola, S.; Quick R. Impact of a hygiene curriculum and the installation of simple handwashing and drinking water stations in rural Kenyan primary schools on student health and hygiene practices. Am. J. . Trop Med Hyg. 87:594-601.

27. Zhang, C.; Mosa, A.J.; Hayward, A.S.; Mathews SA. Promoting clean hands among children in Uganda: A school-based intervention using "tippy-taps". BMC Public Health. (127):586-589.

28. Maeckelberghe E, Schro P. Covid-19: a test for our humanity. Eur J Public Health. 2020;

29. Pinckney J. Sickness or Silence: Social Movement Adaptation to COVID-19. 2020;(September).

30. Donovan Óo. The Covid-19 catastrophe, authoritarianism, and refusing to get used to it. 2020;00(00):1-4.

31. WHO. Coronavirus disease ( COVID-19);WHO Report, Global Situation (Africa, Europe, Asia, South-east). 2020;(May 16). Available from: https://www.who.int/docs/default-source/coronaviruse/situation-reports/20200515-covid-19-sitrep-116.pdf?sfvrsn=8dd60956_2

32. Cowell AJ. The relationship between education and health behavior: Some empirical evidence. Heal Econ. 2006;15(2):125- 146.

33. Huda N et al. The Analysis of Attitudes, Subjective Norms, and Behavioral Control on Muzakki 's Intention to Pay Zakah'. Int J Bus Soc Sci. 2012;3(22):271-279.

34. Abdulkareem SA, Augustijn EW, Filatova T, Musial K MY. Risk perception and behavioral change during epidemics: comparing models of individual and collective learning. PLoS ONE. 2020;

35. Zhong BL, Luo W, Li HM, Zhang QQ, Liu XG, Li WT et al. Knowledge, attitudes, and practices towards COVID-19 among Chinese residents during the rapid rise period of the COVID-19 outbreak: a quick online cross-sectional survey. Int J Biol Sci. 2020;(16):1745-52.

\section{Tables}


Table 1: Search strategy.

\begin{tabular}{|c|c|c|}
\hline Databases & Search & Search words/terms \\
\hline PubMed & $\begin{array}{l}\text { Title \& } \\
\text { abstract }\end{array}$ & $\begin{array}{l}\text { Transmission OR spread AND COVID-19 OR COVID OR corona virus, prevent* OR avoidance OR control OR limit AND } \\
\text { COVID-19 OR COVID OR corona virus, community AND transmission OR spread AND COVID-19 OR COVID OR corona } \\
\text { virus, community AND prevention OR avoidance OR control OR limit AND COVID-19 OR COVID OR corona virus, } \\
\text { community OR family OR school OR workplace OR neighbo? OR household OR local AND transmission OR spread } \\
\text { AND COVID-19 OR corona virus, community OR family OR school OR workplace OR neighbourhood OR household OR } \\
\text { local AND prevention OR avoidance OR control OR limit AND COVID-19 OR COVID OR corona virus AND developing } \\
\text { countries OR low income countries OR middle income countries }\end{array}$ \\
\hline
\end{tabular}

CINAHL Title \& Transmission OR spread AND COVID-19 OR COVID OR corona virus, prevent* OR avoidance OR control OR limit AND abstract COVID-19 OR COVID OR corona virus, community AND transmission OR spread AND COVID-19 OR COVID OR corona virus, community AND prevention OR avoidance OR control OR limit AND COVID-19 OR COVID OR corona virus, community OR family OR school OR workplace OR neighbo? OR household OR local AND transmission OR spread AND COVID-19 OR corona virus, community OR family OR school OR workplace OR neighbourhood OR household OR local AND prevention OR avoidance OR control OR limit AND COVID-19 OR COVID OR corona virus AND developing countries OR low income countries OR middle income countries

MEDLINE Title \& Transmission OR spread AND COVID-19 OR COVID OR corona virus, prevent* OR avoidance OR control OR limit AND abstract COVID-19 OR COVID OR corona virus, community AND transmission OR spread AND COVID-19 OR COVID OR corona virus, community AND prevention OR avoidance OR control OR limit AND COVID-19 OR COVID OR corona virus, community OR family OR school OR workplace OR neighbo? OR household OR local AND transmission OR spread AND COVID-19 OR corona virus, community OR family OR school OR workplace OR neighbourhood OR household OR local AND prevention OR avoidance OR control OR limit AND COVID-19 OR COVID OR corona virus AND developing countries OR low-income countries OR middle-income countries

AMED Title \& Transmission OR spread AND COVID-19 OR COVID OR corona virus, prevent* OR avoidance OR control OR limit AND abstract COVID-19 OR COVID OR corona virus, community AND transmission OR spread AND COVID-19 OR COVID OR corona virus, community AND prevention OR avoidance OR control OR limit AND COVID-19 OR COVID OR corona virus, community OR family OR school OR workplace OR neighbo? OR household OR local AND transmission OR spread AND COVID-19 OR corona virus, community OR family OR school OR workplace OR neighbourhood OR household OR local AND prevention OR avoidance OR control OR limit AND COVID-19 OR COVID OR corona virus AND developing countries OR low income countries OR middle income countries

PsychINFO Title, Transmission OR spread AND COVID-19 OR COVID OR corona virus, prevent* OR avoidance OR control OR limit AND abstract COVID-19 OR COVID OR corona virus, community AND transmission OR spread AND COVID-19 OR COVID OR corona \& full virus, community AND prevention OR avoidance OR control OR limit AND COVID-19 OR COVID OR corona virus, article community OR family OR school OR workplace OR neighbo? OR household OR local AND transmission OR spread AND COVID-19 OR corona virus, community OR family OR school OR workplace OR neighbourhood OR household OR local AND prevention OR avoidance OR control OR limit AND COVID-19 OR COVID OR corona virus AND developing countries OR low income countries OR middle income countries

DOAJ Title, Transmission OR spread AND COVID-19 OR COVID OR corona virus, prevent* OR avoidance OR control OR limit AND abstract COVID-19 OR COVID OR corona virus, community AND transmission OR spread AND COVID-19 OR COVID OR corona \& full virus, community AND prevention OR avoidance OR control OR limit AND COVID-19 OR COVID OR corona virus, article community OR family OR school OR workplace OR neighbo? OR household OR local AND transmission OR spread AND COVID-19 OR corona virus, community OR family OR school OR workplace OR neighbourhood OR household OR local AND prevention OR avoidance OR control OR limit AND COVID-19 OR COVID OR corona virus AND developing countries OR low income countries OR middle income countries

Google Title \& Transmission OR spread AND COVID-19 OR COVID OR corona virus, prevent* OR avoidance OR control OR limit AND Scholar abstract COVID-19 OR COVID OR corona virus, community AND transmission OR spread AND COVID-19 OR COVID OR corona virus, community AND prevention OR avoidance OR control OR limit AND COVID-19 OR COVID OR corona virus, community OR family OR school OR workplace OR neighbo? OR household OR local AND transmission OR spread AND COVID-19 OR corona virus, community OR family OR school OR workplace OR neighbourhood OR household OR local AND prevention OR avoidance OR control OR limit AND COVID-19 OR COVID OR corona virus AND developing countries OR low income countries OR middle income countries

EMBASE Title, Transmission OR spread AND COVID-19 OR COVID OR corona virus, prevent* OR avoidance OR control OR limit AND abstract COVID-19 OR COVID OR corona virus, community AND transmission OR spread AND COVID-19 OR COVID OR corona \& full virus, community AND prevention OR avoidance OR control OR limit AND COVID-19 OR COVID OR corona virus, article community OR family OR school OR workplace OR neighbo? OR household OR local AND transmission OR spread AND COVID-19 OR corona virus, community OR family OR school OR workplace OR neighbourhood OR household OR local AND prevention OR avoidance OR control OR limit AND COVID-19 OR COVID OR corona virus AND developing countries OR low income countries OR middle income countries

Reference Title, Transmission OR spread AND COVID-19 OR COVID OR corona virus, prevent* OR avoidance OR control OR limit AND search abstract from other \& full sources article COVID-19 OR COVID OR corona virus, community AND transmission OR spread AND COVID-19 OR COVID OR corona virus, community AND prevention OR avoidance OR control OR limit AND COVID-19 OR COVID OR corona virus, community OR family OR school OR workplace OR neighbo? OR household OR local AND transmission OR spread AND COVID-19 OR corona virus, community OR family OR school OR workplace OR neighbourhood OR household OR local AND prevention OR avoidance OR control OR limit AND COVID-19 OR COVID OR corona virus AND developing countries OR low-income countries OR middle-income countries

Total

records

searched

Total articles

included
Results

1

0

\section{0,100}


Table 2: Summary table/data extraction

Page 11/18 


\begin{tabular}{|c|c|c|c|c|c|c|c|c|c|}
\hline \multirow{3}{*}{$\begin{array}{l}\text { Author \& } \\
\text { year }\end{array}$} & \multicolumn{4}{|l|}{ Population } & \multirow{3}{*}{$\begin{array}{l}\text { Sample } \\
\text { size }\end{array}$} & \multirow{3}{*}{$\begin{array}{l}\text { Study design } \\
\text { \& methods }\end{array}$} & \multicolumn{3}{|c|}{ Objectives/aims } \\
\hline & Participants & Age & Setting & Country & & & $\begin{array}{l}\text { Study } \\
\text { purpose/ }\end{array}$ & Outcomes & Results \\
\hline & & & & & & & Objective & & \\
\hline
\end{tabular}

Yanti. B - Adult $12-65$ Provinces

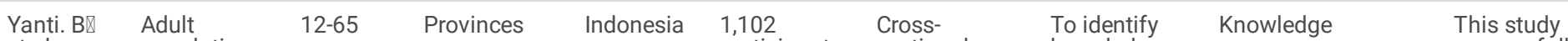

population years

participants

sectional

knowledge,

from 29

design, using

attitudes,

Attitude

$\begin{array}{ll}\text { online closed } & \text { and } \\ \text { questions } & \text { behaviour }\end{array}$

towards the

Behaviour

prevention

of SARS-

CoV-2

transmission

through

social

distancing

during the

COVID-19

pandemic

among the

Indonesian

community $\mathbb{Z}$

successfully

identified 99\%,

and $93 \%$ of

respondents $w$

good knowled

positive attitud

and good beha

towards social

distancing,

respectively. Ar

the respondent

who had good

knowledge, 58

showed positiv

attitudes and $\mathrm{C}$

good behavior.

The vast majo respondents $\mathrm{W}$

had positive

attitudes show

good behavior

$(96.7 \%)$. \

\begin{tabular}{|c|c|c|c|c|c|c|c|}
\hline $\begin{array}{l}\text { Usman et } \\
\text { al., } \\
(2020)\end{array}$ & Vendors & $\begin{array}{l}\text { Age } \\
\text { category } \\
<20 \text { to } \\
>60\end{array}$ & $\begin{array}{l}\text { Rural } \\
\text { market in a } \\
\text { municipality }\end{array}$ & Uganda & 248 & $\begin{array}{l}\text { Descriptive } \\
\text { cross- } \\
\text { sectional } \\
\text { study Using } \\
\text { online } \\
\text { questionnaire }\end{array}$ & $\begin{array}{l}\text { The study } \\
\text { aimed to } \\
\text { assess the } \\
\text { role of } \\
\text { information } \\
\text { sources, } \\
\text { education } \\
\text { level, and } \\
\text { phone } \\
\text { internet } \\
\text { connectivity } \\
\text { in } \\
\text { influencing } \\
\text { COVID-19 } \\
\text { knowledge } \\
\text { among the } \\
\text { rural market } \\
\text { vendors; and } \\
\text { the } \\
\text { relationship } \\
\text { existing } \\
\text { between } \\
\text { knowledge, } \\
\text { attitude, and } \\
\text { practices } \\
\text { among } \\
\text { them. }\end{array}$ \\
\hline
\end{tabular}

Knowledge the majority of

rural market

vendors had

sufficient

information

regarding COV

19.

The general

percentage scc

for knowledge,

attitude, and

practices were

$(75.57,82.6$, ar

$76.50 \%$

respectively). 7

was a positive

correlation bet

attitude and

practices ( $r=0$

$=0.007$ ), as $\mathrm{W} \epsilon$

their knowledg

with practices

$0.29, p<0.001$

The majority o people in the

population did

have their phor

connected to th

internet (OR =

$95 \% \mathrm{Cl}: 1.16-3$

$=0.01$ ). The

majority of pec

received their

information

regarding $\mathrm{COV}$

from one sourc

(radio) $(\mathrm{OR}=1$

Ssebuufu Ugandans Above Nation wide Uganda 1763

et al.

(2020)

\section{8 years}

sectional
study. Using
online survey

online survey

\section{To}

assessing

the

awareness,

knowledge,

attitude and

practices

towards

measures

for

prevention

of the

spread of

Covid-19

amongst

Ugandans.
Knowledge

Attitude

Behaviour

$97.6 \%$ were aw of the current pandemic.

$83.9 \%$ of participants ha good knowledc score $(21.8 / 27$

$72.4 \%$ had a gr attitude

$85.3 \%$ were practicing measures to prevent the spr 
of Coronavirus disease

Being a health worker was

significantly

associated wit

high knowledg

(aOR: 6 (3.32-1

; a good attituc

(aOR: 2.5(1.68

3.8)]) and goo

practice(aOR: ?

(1.95-4.2)

On contrary, be driver, business entrepreneur al security persor were found to I less rate in

awareness,

knowledge, att and practice

\begin{tabular}{|c|c|c|c|c|c|c|c|c|c|}
\hline $\begin{array}{l}\text { Hager E. } \\
\text { et al. } \\
(2020)\end{array}$ & $\begin{array}{l}\text { Egyptians } \\
\text { and } \\
\text { Nigerians }\end{array}$ & $\begin{array}{l}18-39 \\
(>17)\end{array}$ & $\begin{array}{l}\text { Country } \\
\text { wide. i.e } \\
\text { across }\end{array}$ & $\begin{array}{l}\text { Nigeria } \\
\text { and } \\
\text { Egypt }\end{array}$ & 1437 & $\begin{array}{l}\text { Cross- } \\
\text { sectional } \\
\text { survey. Using } \\
\text { online } \\
\text { questionnaire }\end{array}$ & $\begin{array}{l}\text { To assess } \\
\text { the } \\
\text { knowledge, } \\
\text { attitude, and } \\
\text { perceptions } \\
\text { of Egyptians } \\
\text { and } \\
\text { Nigerians } \\
\text { towards the } \\
\text { COVID-19 } \\
\text { pandemic }\end{array}$ & $\begin{array}{l}\text { knowledge, } \\
\text { attitude, } \\
\text { perceptions }\end{array}$ & $\begin{array}{l}\text { The mean } \\
\text { knowledge sco } \\
\text { was } 14.7 \pm 2.3 \text {. } \\
\text { The majority o } \\
\text { respondents } \\
(61.6 \%) \text { had a } \\
\text { satisfactory } \\
\text { knowledge of } t \\
\text { disease. }\end{array}$ \\
\hline
\end{tabular}

Age (18-39 ye education

(College/bach€ and backgrour respondents $w$ factors influen knowledge lev

The attitude of most responde (68.9\%) towarc instituted prev measures was satisfactory wi average attituc score of $6.9 \pm$

The majority o respondents ( 9 practiced selfisolation and s distancing

Only $36 \%$ follo health

recommendati

The perception most responde $(62.1 \%)$ on the global efforts : controlling the and preventing further spread satisfactory wi average score । $10.9 \pm 2.7$.

Only $22 \%$ of th respondents $\mathrm{W}$ satisfied with $t$ country's hand of the pandem

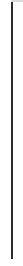

L

\begin{tabular}{|c|c|c|c|c|}
\hline $\begin{array}{l}\geq 20 \\
\text { years. }\end{array}$ & $\begin{array}{l}\text { Country } \\
\text { wide. i.e } \\
\text { across }\end{array}$ & $\begin{array}{l}\text { South } \\
\text { Korea, } \\
\text { Ethiopia } \\
\text { \& DRC }\end{array}$ & $\begin{array}{l}748 \text { with } \\
370 \text { from } \\
\text { South } \\
\text { Korea, } 175 \\
\text { from } \\
\text { Ethiopia, } \\
\text { and 203 } \\
\text { from DRC. }\end{array}$ & $\begin{array}{l}\text { Cross- } \\
\text { sectional } \\
\text { study, using } \\
\text { questionnaire } \\
\text { survey }\end{array}$ \\
\hline
\end{tabular}

To identify
differences
in trust level
of COVID-19
diagnosis,
recent
healthcare
utilization

Levels of trust in healthcare facilities regarding COVID-

19 diagnosis

COVID-19-related

experiences, information,
South Korea showed higher COVID-19

prevention suc hand washing, mask wearing, 


experiences, $\quad \begin{aligned} & \text { knowledge, and } \\ & \text { and COVID- }\end{aligned}$ practice of
19-related
knowledge,
information,
and
prevention
practices in
South Korea,
Ethiopia, and
DRC.
To identify
factors
influencing
trust level in
healthcare
facilities
regarding
COVID-19
diagnosis

etc. than Ethio and DRC.

\begin{tabular}{|c|c|c|c|c|c|c|c|}
\hline $\begin{array}{l}\text { Doherty } \\
\text { et al., } \\
(2020)\end{array}$ & $\begin{array}{l}\text { Adult } \\
\text { population }\end{array}$ & $\begin{array}{l}16-61 \\
\text { years }\end{array}$ & states & Nigeria & 387 & $\begin{array}{l}\text { Cross } \\
\text { sectional } \\
\text { design using } \\
\text { online survey }\end{array}$ & $\begin{array}{l}\text { To evaluate } \\
\text { the } \\
\text { knowledge, } \\
\text { impacts, and } \\
\text { government } \\
\text { intervention } \\
\text { dur- ing the } \\
\text { pandemic. }\end{array}$ \\
\hline
\end{tabular}

knowledge, attitude/perception, practice and

impact

$85 \%$ of the responders

know aboı

preventive measure of th $\epsilon$

disease $\mathbb{Z}$

$94 \%$ indicated social distanci can help preve spread of the $v$

$52 \%$ of respon reported that th do cover their mouth with a t or

handkerchief/ $\epsilon$ when sneezing coughing, 33\% respondents indicated most the time, $13 \%$ indicated occasionally a $2 \%$ do not cove their mouth.

$67 \%$ wash thei hands with soc

$70 \%$ either wea PPE always, $\mathrm{m}$ of the time according to ri: assessment or occasion- ally. 
Three-quarters the respondent reported that th sanitize/wash hands after us an automated machine

(ATM/POS); wl those that

sanitize/wash hands after

touching Niger

currency were

Majority of the respondents (o

90\%) acknowle that staying at home will help reduce the spre of COVID -19 . above half of $t$ respondents $\mathrm{ct}$ social distanci movement

restriction and

of face mask a

precautionary

measures they

against COVID

infection

The knowledg $\epsilon$ the outbreak of

COVID-19 was

fluenced by the

$(p<0.05)$, gen

$<0.05$ ), level of education $(p<$ $0.05)$, marital s $(p<0.05)$ and employment st $(p<0.05)$. Bott $(p=0.03)$ and of education ( 0.05 ) influence respiratory anc personal hygie the respondent

Table 3: MMAT 


\begin{tabular}{|c|c|c|c|c|c|c|}
\hline \multirow{2}{*}{$\begin{array}{l}\text { Name of study } \\
\text { author }\end{array}$} & \multirow[t]{2}{*}{ Type of study } & \multirow[t]{2}{*}{ Methodological quality criteria } & \multicolumn{4}{|c|}{ Responses } \\
\hline & & & Yes & No & $\begin{array}{l}\text { Can't } \\
\text { tell }\end{array}$ & Comments \\
\hline \multirow[t]{5}{*}{$\begin{array}{l}\text { Yanti. B囚et.al., } \\
(2020)\end{array}$} & \multirow[t]{5}{*}{$\begin{array}{l}\text { Cross-sectional design, using online } \\
\text { closed questions }\end{array}$} & $\begin{array}{l}\text { 4.1. Is the sampling strategy relevant to address the } \\
\text { research question? }\end{array}$ & Yes & & & \\
\hline & & $\begin{array}{l}\text { 4.2. Is the sample representative of the target } \\
\text { population?区 }\end{array}$ & Yes & & - & \\
\hline & & 4.3. Are the measurements appropriate?】 & Yes & & - & \\
\hline & & 4.4. Is the risk of nonresponse bias low? & Yes & & - & \\
\hline & & $\begin{array}{l}\text { 4.5. Is the statistical analysis appropriate to answer the } \\
\text { research question? }\end{array}$ & Yes & & - & \\
\hline \multirow[t]{5}{*}{$\begin{array}{l}\text { Usman et al., } \\
\text { (2020) }\end{array}$} & \multirow[t]{5}{*}{ Descriptive cross-sectional study } & $\begin{array}{l}\text { 4.1. Is the sampling strategy relevant to address the } \\
\text { research question? }\end{array}$ & Yes & & - & \\
\hline & & 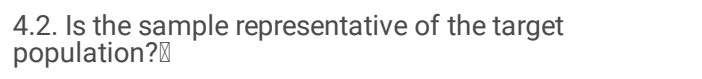 & No & & - & $\begin{array}{l}\text { Not clearly } \\
\text { indicated }\end{array}$ \\
\hline & & 4.3. Are the measurements appropriate?囚 & Yes & & - & \\
\hline & & 4.4. Is the risk of nonresponse bias low? $₫$ & Yes & & - & \\
\hline & & $\begin{array}{l}\text { 4.5. Is the statistical analysis appropriate to answer the } \\
\text { research question?』 }\end{array}$ & Yes & & - & \\
\hline \multirow[t]{5}{*}{$\begin{array}{l}\text { Ssebuufu et al. } \\
(2020)\end{array}$} & \multirow[t]{5}{*}{ Cross-sectional study } & $\begin{array}{l}\text { 4.1. Is the sampling strategy relevant to address the } \\
\text { research question? }\end{array}$ & Yes & & - & \\
\hline & & $\begin{array}{l}\text { 4.2. Is the sample representative of the target } \\
\text { population?区 }\end{array}$ & Yes & & - & \\
\hline & & 4.3. Are the measurements appropriate?】 & Yes & & - & \\
\hline & & 4.4. Is the risk of nonresponse bias low?】 & Yes & & - & \\
\hline & & $\begin{array}{l}\text { 4.5. Is the statistical analysis appropriate to answer the } \\
\text { research question?区 }\end{array}$ & Yes & & - & \\
\hline \multirow[t]{5}{*}{$\begin{array}{l}\text { Hager E. et al. } \\
(2020)\end{array}$} & \multirow[t]{5}{*}{ Cross-sectional study } & $\begin{array}{l}\text { 4.1. Is the sampling strategy relevant to address the } \\
\text { research question? }\end{array}$ & Yes & & - & \\
\hline & & $\begin{array}{l}\text { 4.2. Is the sample representative of the target } \\
\text { population?区 }\end{array}$ & Yes & & - & \\
\hline & & 4.3. Are the measurements appropriate?』 & Yes & & - & \\
\hline & & 4.4. Is the risk of nonresponse bias low? & Yes & & - & \\
\hline & & $\begin{array}{l}\text { 4.5. Is the statistical analysis appropriate to answer the } \\
\text { research question?囚 }\end{array}$ & Yes & & & \\
\hline \multirow[t]{5}{*}{$\begin{array}{l}\text { Doherty et al. } \\
\text { (2020) }\end{array}$} & \multirow[t]{5}{*}{ Cross-sectional study } & $\begin{array}{l}\text { 4.1. Is the sampling strategy relevant to address the } \\
\text { research question? }\end{array}$ & Yes & & - & \\
\hline & & $\begin{array}{l}\text { 4.2. Is the sample representative of the target } \\
\text { population?区 }\end{array}$ & Yes & & - & \\
\hline & & 4.3. Are the measurements appropriate?囚 & Yes & & - & \\
\hline & & 4.4. Is the risk of nonresponse bias low? & Yes & & & \\
\hline & & $\begin{array}{l}\text { 4.5. Is the statistical analysis appropriate to answer the } \\
\text { research question?】 }\end{array}$ & Yes & & & \\
\hline
\end{tabular}

\section{Figures}




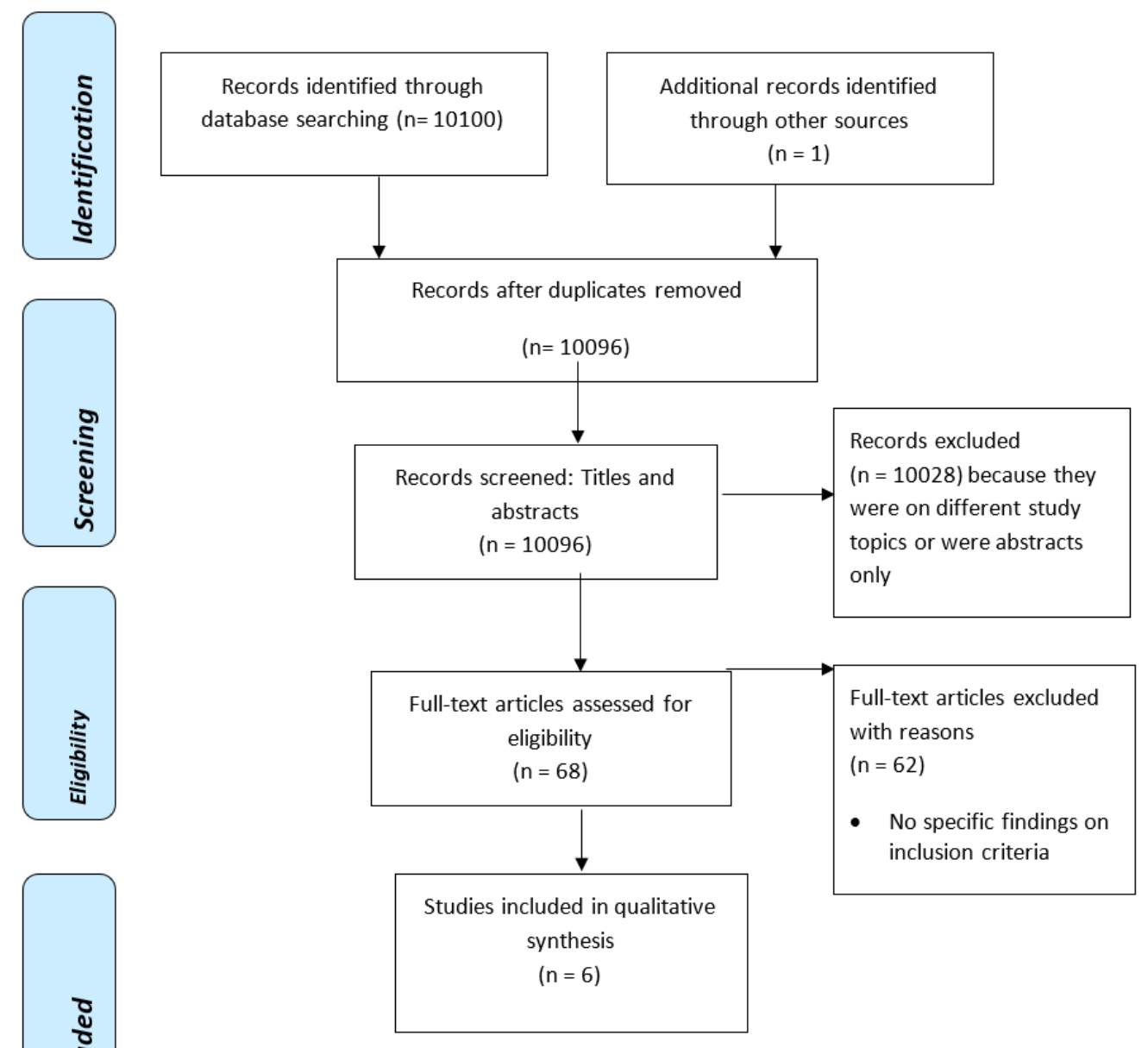

Figure 1

PRISMA flow diagram showing the number of articles retrieved, retained, excluded with justifications rendered for every action. Out of 10100 articles identified, only six finally met the inclusion criteria and synthesised qualitatively.

\section{Levels of KAP on Community Based Interventions for Preventing Covid}

19

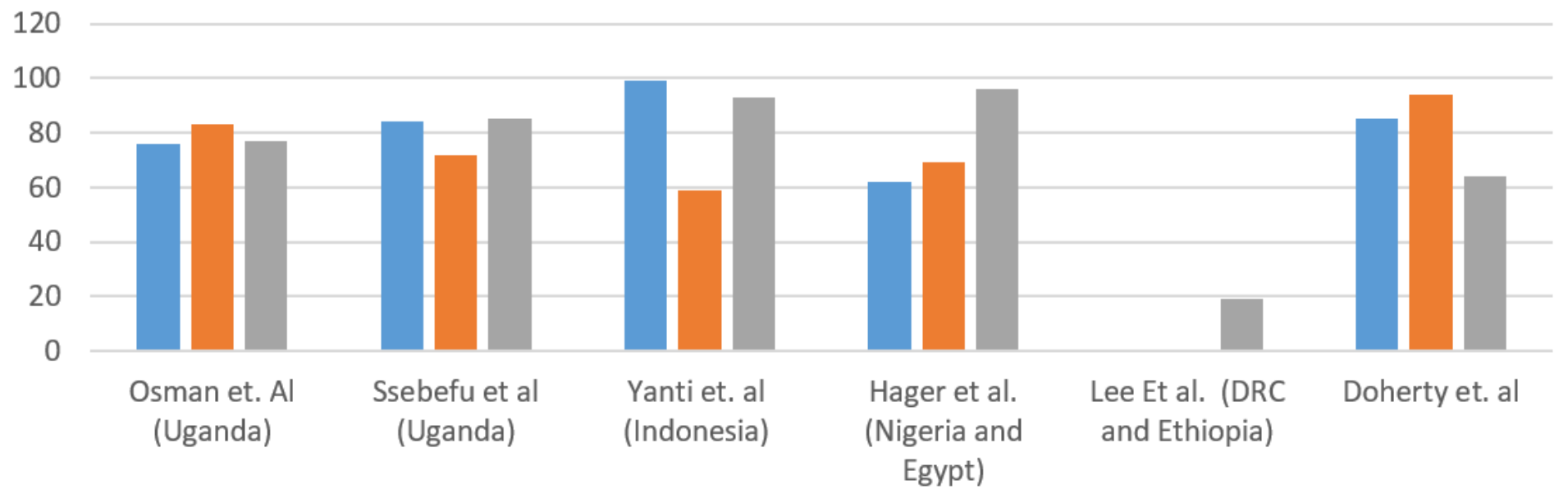

Knowlegde (\%) —Attitude (\%) —Practice (\%) 
Level of KAP on community-based interventions for preventing COVID-19 Lee et al., 2020 only looked at practice while the rest of the studies looked at level of KAP. Practice on community-based intervention was lowest in a study by Lee et al., 2020. Level of knowledge was highest in a study by Yanti et al., 2020. The level of attitude was highest in a study by Doherty et al., 2020.

\section{Community Based Intervations for preventing Covid-19}

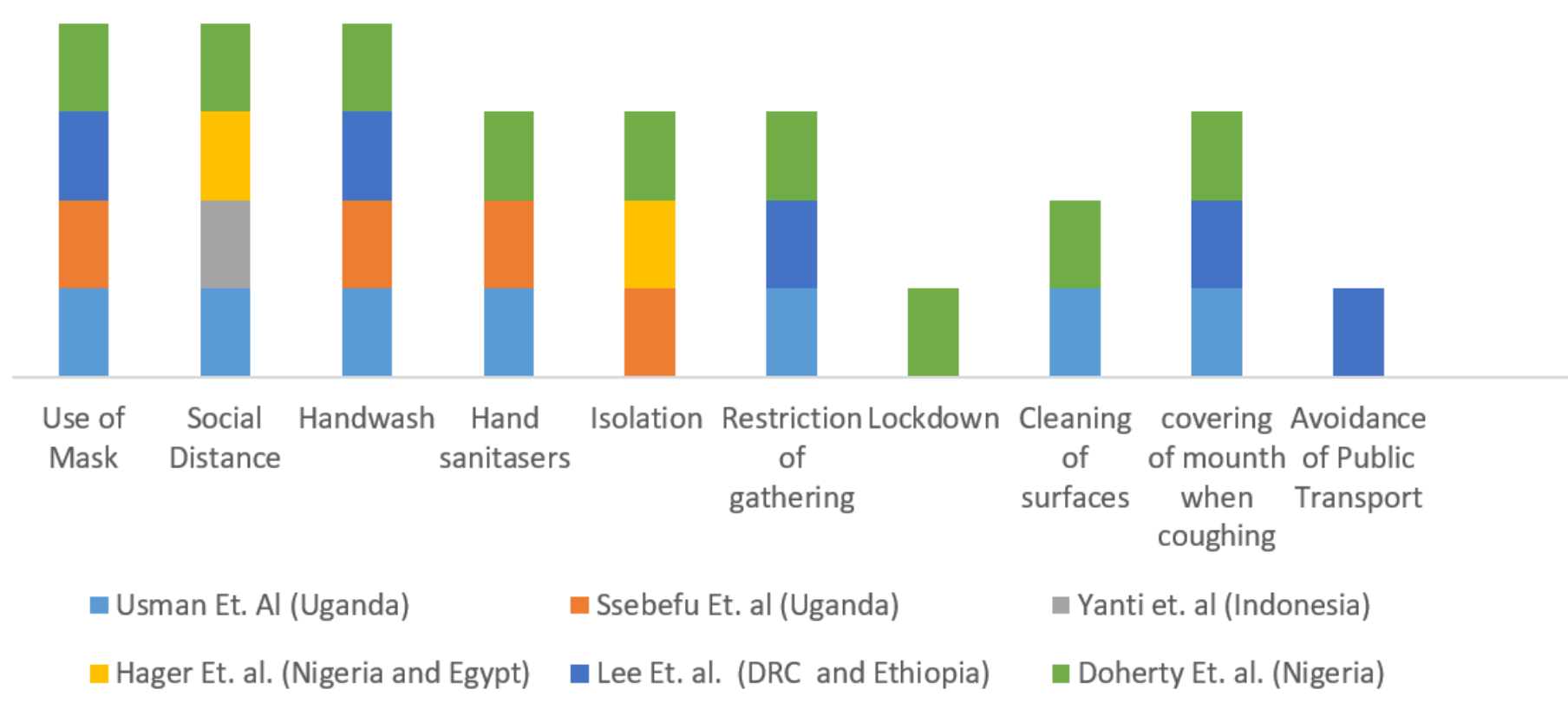

Figure 3

Types of community-based intervention for preventing COVID-19 Ten community-based interventions identified. Use of masks, social distancing and hand washing were the most commonly studied intervention in the articles under review. Lockdown and avoidance of public transport were the least studied 